\section{Beefing about cattle farming}

\section{Verner Wheelock}

Beyond Beef: The Rise and Fall of the Cattle Culture. By Jeremy Rifkin. Thorsons (HarperCollins): 1994. Pp. 353. 18.99 (pbk). Published last year in the United States by Penguin.

JEREMY Rifkin has collected a mass of information portraying all that is bad about beef production. According to him, there are today 1.28 billion cattle in the world. Cattle use land that could be much more efficiently used for other purposes. Much of the destruction of the Amazon cases of infection with Escherichia coli

0157, a particularly virulent pathogen with beef one of its main sources; publication of the report of the Beef Tribunal in Ireland, which has confirmed the exist- ence of many dubious practices within the industry; and the growing concern about animal welfare, especially during transport. A British visitor to Greece recently described in a radio interview how she had seen a lorry load of dead cattle that had suffocated because they were packed too closely together.

It would be wrong, of course, to deduce from this book that all cattle are badly treated and that all beef is a threat to human health. Nevertheless, Rifkin makes many valid points. The book will certainly provide ammunition for those who object to the use of meat in the human diet. It should be read by anyone who has an interest in food and in the way it is produced. Above all, it should be essential reading for all those involved in any aspect of the beef industry. If beef is to have a future, then the issues raised must be addressed and the allegations answered.

Verner Wheelock is at Albert Mill, 10 Hey Street, Bradford, West Yorkshire BD7 1DQ, UK.

\section{IMAGE UNAVAILABLE FOR COPYRIGHT REASONS}

\section{Threat to human health?}

rainforest during the 1970 s has been attributed to large-scale cattle farming. The shortage of human food is exacerbated because of the large amounts of grain used to feed the cattle. About 60 million tonnes of methane are released into the atmosphere annually, thereby contributing to global warming.

The cattle themselves are subject to considerable ill-treatment, as the following allegation about US practice shows.

Because the journey to the slaughterhouse is often a rough and brutal one, animals frequently fall and are trampled upon inside the trucks, suffering broken legs or pelvis. Unable to rise these animals are known as 'downers'. Although downed animals are frequently in severe pain, they are rarely euthanised [sic] or anaesthetised, as that would translate into a lost carcass and additional expenses. Often spreadeagled on the floor of the trailers, unable to stand or walk, these hapless animals are chained by their broken legs and dragged from the truck onto the loading ramp to await their turn for slaughter.

\title{
Strategies for living together
}

\section{David L. Hawksworth}

Symblotic Interactions. By Angela E. Douglas. Oxford University Press: 1994. Pp. 148. \$45, £29.50 (hbk); \$21.95, $£ 12.50$ (pbk).

THE fundamental biological strategy of symbiosis is only rarely accorded prominence in considerations of ecology or ecosystem processes. Yet lichen symbioses are the major primary producers on eight per cent of the land surface, and algae in coral fix three to four times more carbon than the phytoplankton in all nutrientupwelling regions of the oceans. In adopting a 'process' rather than an 'association' approach, this book is immediately set apart from The Biology of Symbiosis, which the author wrote with Sir David Smith in 1987, and from other texts. Disparate organisms appear side by side in consideration of novel structures and metabolic capabilities, nutritional interactions and the formation and regulation of symbiosis. In a period of biology characterized by increasing specialization, it is refreshing to be able to read in the space of a few lines of luminous bacteria, fish and squids, herbivorous mammal gut processes, root nodules of legumes and lichen thalli.

But what should be the compass of such a title? Douglas prudently rejects mutual benefit as a criterion for symbiosis, and defines symbiosis as "associations between different species that persist for long periods (relative to the generation time of the interacting organisms)". Is this really what de Bary intended in 1879 in explicitly including parasitic relationships?

And what should the partners be called? Douglas refers to the larger organism as the 'host' and the smaller as the 'symbiont'. Contrary to the treatment in The Biology of Symbiosis, this terminology is considered inappropriate for mycorrhizal fungi and plants, but should it really be maintained outside host-parasite relationships? In the case of lichen thalli, the fungal partner is treated as the 'host', yet the structure results only from the interaction, and de Bary himself regarded the algae in lichens as hosts to the fungus. Adoption of the neutral terms 'inhabitant' and 'exhabitant' proposed by $R$. Law and D. H. Lewis in 1983 would have avoided any need for assumptions about relationships, and enabled each partner to be referred to as a 'symbiont'.

This book is most timely. Symbiotic associations are particularly at risk from the loss of biodiversity, as in many cases one inhabitant can form associations with a variety of exhabitants. The complexity, and our level of ignorance, of such associations spring from this book. It will stimulate both aspiring and established biologists.

David L. Hawksworth is in the International Mycological Institute, Bakeham Lane, Egham, Surrey TW20 9TY, UK. 